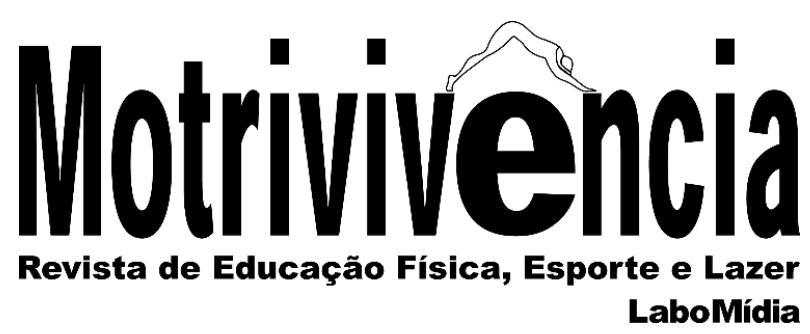

\title{
Para além da legitimidade: a necessidade da Educação Física escolar
}

\section{RESUMO}

A obra "A necessidade histórica da Educação Física na Escola: impasses atuais" (2014), de Rosângela Aparecida Mello, fundamenta-se nos pressupostos da teoria do materialismo histórico e busca recolocar esta concepção nas discussões sobre a Educação Física. $\mathrm{O}$ objetivo central da obra é investigar a necessidade histórica da Educação Física escolar no contexto atual de crise e renovação do capital. Mello expõe um debate acerca da legitimidade da disciplina, deslocando-o para a questão de sua necessidade histórica, elevando a discussão a um novo patamar. Considera que as necessidades são construções históricosociais que buscam, tanto na Educação Física como em qualquer outro campo social, a construção de uma sociedade emancipada. Todavia, dentro de seus limites e possibilidades, a escola e a Educação Física pouco podem contribuir para a superação social radical, visto que só é possível pensar a cultura corporal para a emancipação humana se, de fato, esta for a intenção social.

PALAVRAS-CHAVE: Educação física; Escola; Capitalismo; Emancipação humana

\section{Fernanda Herran Fernandes}

Especialista em Psicologia Histórico-

Cultural

Prefeitura Municipal de Cianorte, Universidade Estadual de Maringá, Maringá, Paraná, Brasil fernanda_herran@hotmail.com https://orcid.org/0000-0003-4410-9342 


\title{
For beyond of legitimacy: the need for Physical Education at school
}

\begin{abstract}
The book, entitled "The historical need for Physical Education in school: current deadlocks" (2014), written by Rosângela Aparecida Mello, is based on the assumptions of the theory of historical materialism and seeks put again this conception in discussions about Physical Education. The objective is to investigate the historical necessity of Physical Education at school in the current context of crisis and capital renewal. The author exposes a debate about the legitimacy of the discipline, presenting the question of its historical necessity, raising the discussion to a new level. The book considers that needs are historical-social constructions that seek the construction of an emancipated society, both in Physical Education and in any other social field. However, through their limits and possibilities, school and Physical Education can contribute little to radical social overcoming, because it is only possible to think of body culture for human emancipation if this is the social intention.
\end{abstract}

KEYWORDS: Physical Education; School; Capitalism; Human emancipation

\section{Más allá de la legitimidad: la necesidad de la Educación Física escolar}

\section{RESUMEN}

El "La necesidad histórica de la Educación Física en la escuela: impases actuales" (2014), de Rosângela Aparecida Mello, se basa en los presupuestos del materialismo histórico y repiensa esta concepción en las discusiones sobre Educación Física. El objetivo es investigar la necesidad histórica de la Educación Física en lo contexto actual de crisis y renovación de lo capital. Mello expone un debate sobre la legitimidad de la disciplina, desplazándola a la cuestión de su necesidad histórica, elevando la discusión a otro nivel. Considera que las necesidades son construcciones histórico-sociales que buscan, en la Educación Física como en cualquier otro campo social, la construcción de una sociedad emancipada. Sin embargo, dentro de sus límites y posibilidades, la educación escolar y la Educación Física puede contribuir poco a la superación social radical, ya que solo es posible pensar en la cultura corporal para la emancipación humana si este es la intención social.

PALABRAS-CLAVE: Educación Física; Escuela; Capitalismo; Emancipación humana 


\section{INTRODUÇÃO}

A obra "A necessidade histórica da Educação Física na escola: os impasses atuais" é resultado da tese de doutorado apresentada pela professora Rosângela Aparecida Mello ao Curso de Pós-Graduação em Educação da Universidade Federal de Santa Catarina (UFSC) em 2009, intitulada "A necessidade histórica da Educação Física na escola: a emancipação humana como finalidade”. Este livro é composto por seis capítulos, distribuídos por 204 páginas e está disponível nas versões impressa e digitalizada, com acesso gratuito no site do Instituto Lukács, editor da obra.

O objetivo central é investigar a necessidade histórica da Educação Física no contexto escolar na conjuntura da atual crise e renovação do capital. Discorre sobre os esforços realizados para justificar a presença e permanência da disciplina na escola, bem como para legitimá-la, pautando-se em pressupostos que conceituam educação como um complexo social de caráter amplo, tendo como uma de suas especificidades a educação escolar.

A obra situa o desenvolvimento teórico-científico da área, perpassando seus momentos predominantes, a função social que ocupa em cada um deles e sua justificativa a favor dos interesses da classe dominante. A superação das proposições na área de Educação Física que a presente obra traz não vem em forma de uma metodologia pronta e acabada para aulas efetivamente práticas na escola, como muito se espera de novas posições teóricas. As análises criteriosas da discussão posta podem ser consideradas avançadas, pois possibilita maior compreensão da Educação Física enquanto prática corporal, bem como os elementos da cultural corporal. Uma elaboração que analisa a especificidade do objeto de estudo da Educação Física - a cultura corporal

- articulando firmemente aos pressupostos teóricos do materialismo histórico. É uma contribuição para a recuperação da matriz teórica marxista, recolocando-a efetivamente nas discussões referentes à Educação Física, buscando avançá-las em relação ao que foi construído a partir da década de 1980.

$\mathrm{Na}$ Introdução de sua obra, Mello (2014) afirma que, ao anunciar a "necessidade histórica" da Educação Física, não pretende fazer uma defesa incondicional da Educação Física "na e da" escola, nem apontar para uma determinação histórica de transformação social fundamentada em uma posição utópica. A autora compreende a escola como uma instituição fundada nesta sociedade que, portanto, possui determinações que partem das relações sociais estabelecidas pelos homens. Sendo assim, a Educação Física enquanto disciplina escolar acompanha as modificações da organização social capitalista, modificando seus conteúdos, sua forma de aplicá-los, como também as disposições legais dessa disciplina no âmbito escolar, conformando-se à lógica social. 
Neste sentido, a hipótese de Mello (2014) é de que a legitimidade da Educação Física é dada pelas necessidades de manutenção das relações sociais vigentes e não pela necessidade de seu conteúdo específico. Portanto, é uma impossibilidade histórica buscar a legitimação da Educação Física nela mesma, visto os limites de uma sociabilidades que não traz como perspectiva nem a emancipação humana e nem mesmo este conteúdo especifico, seja pelo modelo conservador ou pela perspectiva de emancipação.

Ao expor os capítulos que compõem o livro, Mello (2014) apresenta a intenção de recolocar a concepção materialista histórica nas discussões sobre Educação Física, apreendendo o significado de educação, de ser social, do desenvolvimento histórico das atividades físicas e práticas corporais, à luz do materialismo histórico. Seu empenho passa pela crítica, no sentido de superação e avanço, das discussões da área a partir da década de 1980.

No primeiro capítulo, intitulado A práxis legitimadora da educação física na escola, apresenta a discussão da busca pela legitimidade da Educação Física na escola a partir das mudanças que ocorreram na área. Destacam-se as discussões de Valter Bracht (1987; 1989; 1992; 1993; 1996; 1997; 1999a; 1999b; 2000; 2001; 2003; 2006), pesquisador que está entre as principais referências da área e que manteve uma discussão sistemática sobre "identidade e legitimidade" da Educação Física.

A autora afirma que esta busca está fadada ao fracasso, pois o problema não está apenas na especificidade da Educação Física e naquele que está responsável por ela, mas sim na escola edificada na sociedade capitalista. Para ela, a legitimidade da Educação Física diz respeito a questões políticas e de Estado. Sendo assim, é dada pelas necessidades de manutenção das relações sociais capitalistas e não pela necessidade de seu conteúdo específico. Portanto, é uma impossibilidade histórica legitimar a Educação Física a partir dela mesma.

Neste sentido, uma perspectiva de pesquisa crítica e revolucionária não deve perguntar pela legitimidade da Educação Física, mas por sua necessidade histórica e por qual projeto histórico de sociedade se objetiva. Neste aspecto, o livro propõe um avanço em relação ao modo com concebe a Educação Física escolar.

O segundo capítulo, intitulado A gênese ontológica da educação física, é onde autora discorre primeiramente sobre o desenvolvimento contraditório do ser social, problematizando as relações entre objetividade/subjetividade, sujeito/objeto, teoria/prática, indivíduo/sociedade, corpo/consciência, trabalho intelectual/trabalho manual, tratando como contradições no processo de construção do ser social que se constituem em unidades. Estes elementos têm origem no ato fundante do ser social que, em última instância, define e determina toda a práxis humana: o trabalho de caráter ontológico. A ênfase da discussão destas categorias se justifica pelo fato de serem estes 
os elementos que aparecem nas discussões dos autores da Educação Física, nos artigos do Congresso Brasileiro de Ciências do Esporte (CONBRACE) analisados pela autora.

Posteriormente, Mello (2014) considera a Educação Física como um dos complexos que acompanham todo o processo de desenvolvimento deste ser social. A construção da Educação Física se efetiva no processo de desenvolvimento do ser humano e o acompanha mediante as transformações ocorridas nesse processo. Neste sentido, a Educação Física tal como a conhecemos na sociedade capitalista não é natural e sim histórica, com função social transformada, fruto do desenvolvimento complexo e contraditório do ser social, provocado por ele próprio, diretamente relacionado com a totalidade social construída.

O capítulo três tem por título A natureza da educação, que trata da concepção de educação na perspectiva do materialismo histórico. Para esta discussão, Mello (2014) opta por dialogar com as elaborações teóricas de Dermeval Saviani (1987; 1991; 1997; 1999; 2001), apontando críticas pertinentes e decisivas a este autor no que se refere às suas compreensões de educação, trabalho, escola, afetando assim a Educação Física.

A referência a esse autor se deve ao fato de ter ele fundamental importância nas discussões sobre educação a partir da matriz teórica marxista, desde a década de 1980. E mais ainda, por ser uma das referências na tentativa de mudança de paradigma da Educação Física no período de sua "crise", influenciando a construção da Pedagogia Crítico-Superadora na Educação Física, considerada como única concepção que se fundamenta no "materialismo histórico dialético".

O capítulo quarto aborda A gênese e o desenvolvimento da educação física moderna, trazendo à tona a função social que essa disciplina pedagógica assumiu ao ser incorporada à escola, como também suas funções no desenvolvimento da sociabilidade no capitalismo e no atendimento de suas necessidades.

A análise parte da inclusão da Educação Física como disciplina escolar no final do século XIX, momento em que alguns Estados tentavam organizar os Sistemas Nacionais de Ensino. Tais discussões sobre a educação em geral e outros setores sociais acompanharam e foram determinadas pelo movimento de expansão do capital daquele período.

Em A educação física e a reestruturação produtiva contemporânea, quinto capítulo, é discutido com maior atenção sobre o que representou o "movimento crítico" da Educação Física na sociedade contemporânea. São mencionados alguns dos principais pesquisadores brasileiros e suas respectivas concepções teóricas, que estiveram preocupados em fazer a superação de uma concepção voltada à aptidão física e vinculada basicamente à saúde e ao esporte.

Tais posicionamentos direcionam diferentes propostas pedagógicas que explicitam divergências teóricas dentro do próprio grupo de professores que participaram do "movimento 
crítico", que resultaram em concepções que se tornaram referências para o desenvolvimento da Educação Física e que balizam os debates teóricos até os dias de hoje.

Atrelado ao movimento de globalização, as perspectivas que apontavam para uma crítica mais radical da sociedade capitalista acabam por perder espaço para aquelas que defendem a sociabilidade e outras que se autodenominam de críticas, porém trabalham de forma acrítica em relação à forma de ser da lógica dominante do capital. Não poderia ser diferente o fato de os principais documentos que norteiam as práticas educacionais também expressarem a conformação política aos interesses funcionais de manutenção e desenvolvimento da sociedade capitalista.

Esta afirmação é exemplificada pelo delineamento da implementação da Lei de Diretrizes e Bases da Educação Nacional (LDBEN) de 1996, no que concerne à Educação Física. A autora relata que, aquém das discussões realizadas pelos autores do "movimento crítico", as questões relativas à Educação Física não aparecem ou não é lhe conferido a devida importância nos debates para construção da LDBEN.

Em Mudar para que tudo permaneça como está?, sexto e último capítulo do livro, é apresentado um processo de desenvolvimento teórico conhecido como "crítica da crítica", que nos anos de 1990 passa a refletir sobre as problemáticas elaboradas durante o "movimento crítico", no sentido de repensar as denúncias, os debates e refletir sobre os possíveis avanços. Dessas críticas, surgem novas tendências e concepções de Educação Física denominadas tanto como conservadoras, quanto como críticas: a fenomenológica, a sociológica, a cultural, a construtivista, a concepção de aulas abertas, a concepção da saúde renovada, entre outras.

Este processo que se desencadeia na área é, segundo a autora, um retrocesso, lembrando que se situa no contexto do avanço de políticas neoliberais. Para respaldar essa afirmação, são expostas as produções apresentadas no CONBRACE, nos anos de 1999, 2001 e 2003, analisando mais especificamente os GTTs Epistemologia e Escola, em um total de 130 artigos. O objetivo foi buscar informações sobre como os autores têm procurado justificar a Educação Física na escola, quais as referências teórico-metodológicas apresentadas, quais as concepções de Educação Física presentes em suas abordagens, bem como sua compreensão sobre a dicotomia corpo e mente, teoria e prática, indivíduo e sociedade.

A autora considera que a tentativa de abandonar o paradigma da aptidão física para buscar a justificativa da Educação Física pela "cultura corporal do movimento", abandonando também abordagens positivistas e marxistas, muda o enfoque, apontando para a formação de valores, capacidades individuais e interações interpessoais na formação do cidadão. Ou seja, a Educação Física não garante sua especificidade, pois continuam justificando-a pelos mesmos valores e normas de conduta semelhantes àqueles do século XIX, que podem ser trabalhados por qualquer outra 
disciplina. As mudanças realizadas ou pretendidas são apenas ajustes dessa disciplina à reorganização da mesma lógica da sociedade capitalista.

A título de conclusão, Mello (2014) se contrapõe à questão da legitimidade da Educação Física e aponta que mesmo os autores que se posicionaram a favor de uma transformação social, acabaram por defender a cidadania como finalidade da Educação Física, ou seja, a "emancipação política" e não a "emancipação humana".

Sendo assim, a autora desloca a questão da legitimidade para a questão da necessidade histórica da Educação Física, elevando a discussão a um novo patamar. Afirma que as necessidades são construídas pelos homens e eles buscam meios para satisfazê-las, são necessidades históricosociais e, portanto, não naturais. Neste sentido, a necessidade histórica da Educação Física ou de qualquer outro campo social, para aqueles que defendem a superação do capital, é a necessidade da construção da emancipação humana.

Significa, portanto, recolocar no leque de alternativas, para além da necessidade de se reproduzir o capital, prioritariamente a necessidade de emancipação humana, ou seja, ter como finalidade a construção de uma organização social que possibilite a todos os homens usufruir daquilo que o gênero humano tem conquistado.

Expõe ainda que não se deve alimentar ilusões quanto às possibilidades de intervenção dos educadores formais que buscam a emancipação humana. Reconhece que a escola e a Educação Física podem fazer pouco pela superação radical desta sociedade. Concorda com Tonet (2003) que, dentro dos limites e possibilidades, o que se pode fazer são atividades educativas que apontem no sentido da emancipação. Neste sentido, só é possível pensar a cultura corporal para a emancipação humana se o foco e a direção forem a emancipação humana.

Todavia, a tarefa pedagógica de professores que se colocam no campo da crítica radical superadora da ordem social estabelecida não pode se limitar ao ambiente de trabalho, cabe ao revolucionário estabelecer as mediações críticas onde quer que as possibilidades se apresentem.

Por toda a obra, a autora demonstra como os princípios mais caros para a luta dos trabalhadores são apropriados pela lógica do capital, se expressam no interior da elaboração teórica e penetram o sistema educacional chegando à educação física por meio de suas proposições pedagógicas.

As deteriorações das condições de trabalho, a perda de direitos da classe trabalhadora no âmbito global e as possibilidades que o capital possui para se recompor são tão atuais quanto às questões enfrentadas pela Educação Física, como, por exemplo, a luta por sua obrigatoriedade no currículo escolar, a busca pela sua legitimidade e sua necessidade quando se pretende uma superação social. 
Por fim, Mello (2014) mantém acordo com o Coletivo de Autores no que se refere à proposição do conteúdo específico da Educação Física na escola, os "elementos da cultura corporal", podendo esta sistematização ser considerada o ponto de partida para a prática pedagógica da Educação Física escolar, mas de forma alguma esgotando aí suas proposições.

Ao nos depararmos com a obra, de início, talvez, poderíamos esperar respostas e sugestões prontas sobre como desenvolver o trabalho didático-pedagógico na Educação Física escolar a partir do materialismo histórico, considerando a realidade cada vez mais dinâmica e conturbada da sociedade capitalista, bem as dificuldades didático-metodológicas que muitos professores encontram no trabalho pedagógico.

No entanto, o que temos é uma reelaboração do debate teórico da Educação Física de suma importância, em uma perspectiva revolucionária. É possível identificar a presença dos pressupostos do materialismo histórico na forma de análise de todos os capítulos, bem como a articulação constante da organização econômica da sociedade às discussões sobre Educação Física. Podemos ponderar que a maior contribuição desta obra se encontra exposta no segundo capítulo, que situa a Educação Física a partir dos pressupostos do materialismo histórico, considerando-a como produto histórico da sociedade construída pelos homens e compreendendo o ser social em sua gênese ontológica.

Essa rigorosidade teórica é necessária para que se mantenha fiel à perspectiva teórica que se defende, ainda mais quando se trata de uma especialidade, como é a área da Educação Física, um complexo da qual a teoria de Marx não tratou em específico, mas que não pode ser abstraída quando se busca compreender o ser social e a realidade concreta em que este ser vive e se relaciona.

Nisto se destaca o esforço empreendido pela autora, considerando que até o momento esta delimitação teórica não se efetivou na área, mesmo diante de diversas tentativas. A retomada que a autora faz na teoria marxiana não está presente, de forma geral, nem mesmo em trabalhos da área que se identificam com esta concepção teórica. Observa-se um movimento na Educação Física em busca por uma perspectiva crítica, algumas vezes posicionando-se no campo da esquerda, mas que se distanciam da compreensão de categorias fundamentais das elaborações teóricas de Marx.

Dado o fato de que esta obra é fruto de uma tese defendida já a mais de dez anos e que uma de suas principais discussões tem por base a leitura analítica de artigos apresentados aos GTTS Escola e Epistemologia do evento do CONBRACE dos anos de 1999, 2001, 2003. Dessa forma, se coloca a necessidade de atualização destas análises a partir das edições posteriores ao período selecionado. Por isso, uma sugestão de estudo se volta à verificação das tendências que se apresentam no atual momento de produção científica da área de acordo com os objetivos buscados pela autora, quais sejam a justificativa da Educação Física na escola, os pressupostos teórico- 
metodológicos que têm se apresentado e as concepções de Educação Física que se fazem presentes nas abordagens propostas às práticas pedagógicas.

Podemos considerar que a discussão proposta pela autora ainda se faz atual e imprescindível, visto que avançou em relação à superação e demarcação do caráter materialista da história no desenvolvimento da Educação Física escolar frente às teorias críticas. No entanto, há um incansável caminho pela frente, dados os problemas que se apresentam tanto aos pesquisadores da área, no que diz respeito à produção do conhecimento e aos encaminhamentos dos documentos educacionais mais recentes, quanto aos professores de Educação Física no espaço escolar em sua realidade imediata.

Assim, a partir da presente discussão sobre a gênese ontológica da Educação Física, nos é colocada a necessidade dar continuidade às elaborações teóricas e metodológicas acerca do desenvolvimento histórico dos elementos que permeiam o ensino da Educação Física escolar, indo além dos objetivos na qual a obra se limitou a cumprir. Neste sentido, propõem-se uma abordagem com maior ênfase aos conteúdos específicos da Educação Física, suas características e objetivos próprios, associados às necessidades sociais que lhes foram impostos. Somam-se a isto a necessidade de aprofundamento sobre as particularidades do desenvolvimento infantil, tendo por base a compreensão do desenvolvimento do ser social apresentado em conformidade com as proposições do materialismo histórico. Sobretudo, trata-se de um trabalho coletivo para aqueles que pensam e buscam uma forma social para além da sociedade do capital, mas que compreendem os limites e possibilidades dos espaços que ocupam.

O livro não apenas conta a história da Educação Física moderna, enquanto disciplina escolar, mas defini sua função social no capitalismo. Podemos considerar o presente trabalho como uma síntese do pensamento marxiano atrelado às problemáticas da área, como ponto de partida para aqueles que pretendem compreender a prática pedagógica na Educação Física segundo este referencial teórico. 


\section{REFERÊNCIAS}

BRACHT, Valter. A criança que pratica esporte respeita as regras do jogo... capitalista. In: OLIVEIRA, Vitor Marinho de (org.); FARIA JUNIOR, Alfredo Gomes de (coord.). Fundamentos Pedagógicos. Educação Física. Rio de Janeiro: Ao Livro Técnico, 1987.

BRACHT, Valter. Educação Física: a busca da autonomia pedagógica. Revista da Educação Física/UEM, Maringá, v. 1, n. 0, p. 28-33, 1989.

BRACHT, Valter. Educação Física e aprendizagem social. Porto Alegre: Magister, 1992.

BRACHT, Valter. Educação Física/ciências do esporte: que ciência é essa? Revista Brasileira de Ciências do Esporte. Campinas, v. 13, n. 1, p. 87-101, 1993.

BRACHT, Valter. Educação Física no $1^{\circ}$ grau: conhecimento e especificidade. Revista Paulista de Educação Física. São Paulo: Escola de Educação Física da Universidade de São Paulo, supl. p. 2328, 1996.

BRACHT, Valter. Epistemologia da Educação Física. In: CARVALHO, Máuri de; MAIA, Adriano (org). Ensaios: educação física e esporte. Vitória: UFES, Centro de Educação Física e Desportos, 1997.

BRACHT, Valter. Educação Física e ciência: cenas de um casamento (in)feliz. Ijuí: Editora da Unijuí, 1999a.

BRACHT, Valter. Educação Física e esporte: intervenção e conhecimento. Revista da Educação Física/UEM. Maringá, v. 10, n. 1, p. 95-100, 199 b.

BRACHT, Valter. Educação Física e ciência: cenas de um casamento (in)feliz. Revista Brasileira de Ciência do Esporte. Campinas: Autores Associados, v. 22, n. 1, p. 53-63, 2000.

BRACHT, Valter. Saber e fazer pedagógicos: acerca da legitimidade da Educação Física como componente curricular. In: CAPARROZ, Francisco Eduardo (org.). Educação Física Escolar: política, investigação e intervenção. Vitória: Proteoria, v. 2001.

BRACHT, Valter; ALMEIDA, Felipe Quintão. A política de esporte escolar no Brasil: a pseudovalorização da Educação Física. Revista Brasileira de Ciência do Esporte. Campinas: Autores Associados, v.24, n. 3, p. 87-101, 2003.

BRACHT, Valter; ALMEIDA, Felipe Quintão. Emancipação e diferença na educação: uma leitura com Bauman. Campinas: Autores Associados, 2006.

COLETIVO DE AUTORES. Metodologia do ensino da Educação Física. São Paulo: Cortez, 1992.

MELLO, Rosângela Aparecida. A necessidade histórica da Educação Física na escola: a emancipação humana como finalidade.2009. Tese (Doutorado em Educação) - Universidade Federal de Santa Catarina, Florianópolis, 2009. 
MELLO, Rosângela Aparecida. A necessidade histórica da Educação Física na escola: os impasses atuais. São Paulo: Instituto Lukács, 2014.

SAVIANI, Dermeval. A nova lei da educação: trajetória, limites e perspectiva. Campinas: Autores Associados, 1997.

SAVIANI, Dermeval. Ensino público e algumas falas sobre universidade. São Paulo: Cortez e Autores Associados, 1987.

SAVIANI, Dermeval. Escola e democracia: teorias da educação, curvatura da vara, onze teses sobre educação e política. 32. ed. Campinas: Autores Associados, 1999. (Coleção: Polêmicas do Nosso Tempo).

SAVIANI, Dermeval. Ética, educação e cidadania. Congresso Nacional de Educação para o Pensar e Educação Sexual. Florianópolis, 23-26 de julho de 2001.

SAVIANI, Dermeval. Pedagogia Histórico-Crítica: primeiras aproximações. São Paulo: Cortez; Autores Associados, 1991. (Coleção: Polêmicas do Nosso Tempo).

TONET, Ivo. A educação numa encruzilhada. Revista de Estudos da Educação. Maceió, v. 11, n. 19, p. 33-53, dez. 2003.

\section{NOTAS DE AUTOR}

AGRADECIMENTOS - Não se aplica.

CONTRIBUIÇÃO DE AUTORIA - Não se aplica.

FINANCIAMENTO - Não se aplica.

CONSENTIMENTO DE USO DE IMAGEM - Não se aplica.

APROVAÇÃO DE COMITÊ DE ÉTICA EM PESQUISA - Não se aplica.

CONFLITO DE INTERESSES - Não há conflito de interesses.

\section{LICENÇA DE USO}

Os autores cedem à Motrivivência - ISSN 2175-8042 os direitos exclusivos de primeira publicação, com o trabalho simultaneamente licenciado sob a Licença Creative Commons Attribution Non-Comercial ShareAlike (CC BY-NC SA) 4.0 International. Esta licença permite que terceiros remixem, adaptem e criem a partir do trabalho publicado, desde que para fins não comerciais, atribuindo o devido crédito de autoria e publicação inicial neste periódico desde que adotem a mesma licença, compartilhar igual. Os autores têm autorização para assumir contratos adicionais separadamente, para distribuição não exclusiva da versão do trabalho publicada neste periódico (ex.: publicar em repositório institucional, em site pessoal, publicar uma tradução, ou 
como capítulo de livro), com reconhecimento de autoria e publicação inicial neste periódico, desde que para fins não comerciais e compartilhar com a mesma licença.

\section{PUBLISHER}

Universidade Federal de Santa Catarina. Programa de Pós-Graduação em Educação Física. LaboMídia - Laboratório e Observatório da Mídia Esportiva. Publicado no Portal de Periódicos UFSC. As ideias expressadas neste artigo são de responsabilidade de seus autores, não representando, necessariamente, a opinião dos editores ou da universidade.

\section{EDITORES}

Mauricio Roberto da Silva, Giovani De Lorenzi Pires, Rogério Santos Pereira.

\section{EDITOR DE SEÇÃO}

Rogério Santos Pereira

\section{REVISÃO DO MANUSCRITO E METADADOS}

João Caetano Prates Rocha; Keli Barreto Santos

\section{HISTÓRICO}

Recebido em: 27 de julho de 2020

Aprovado em: 20 de outubro de 2020 